\title{
DEVELOPMENT OF "PRE-MIX METHOD” FOR MIXING STEEL FIBER REINFORCED CONCRETE WITH NEW MIXING TECHNOLOGY
}

\author{
Prof. Dr. Tek Raj Gyawali
}

\author{
Department of Earthquake Engineering, Khwopa Engineering College
}

\begin{abstract}
When mixing Steel Fiber Reinforced Concrete (SFRC) in conventional mixers, there is limitation of fiber percentage (maximum up to 2.5\%). And, when mixing in newly developed Energy Saving Gravity (ESG) continuous mixer with conventional mix ing method, good quality of SFRC could not be obtained due to blockage problem even for low percentage of fibers when mixing continuously. In order to overcome both of above mentioned problem, new mixing method called "Pre-mix Method" is developed. This paper outlines the mechanism of new mixing technology and application of pre-mix method for mixing SFRC. It is verified that the use of this method has prevailed to make possible of SFRC with increase of fiber percentage up to $4 \%$ in new continuous mixer.
\end{abstract}

Keywords: ESG continuous mixer, SFRC, New mixing mechanism, Inter-particle collision and Impact, Splitting and Re-combination, Pre-mix method

\section{Introduction}

As shown in the Fig 1, let A and B be two particles which are charged into ESG continuous mixer using external energy. When entering into ESG continuous mixer they have possibility of colliding each other before impacting into the inner sloped surface of ESG continuous mixer, case (a), or impacted into surface, case (b); and may collide after bouncing as well, case (c). As shown in the case (d), when two particles are dispersed after collision, they can be collided again with other dispersed particles. Therefore, number of chances for collision for one particle increases when increasing the total number of partic les in materials. Such action of inter-particle collision and impact with surface makes the different types of materials in even distribution when passing through number of units of ESG continuous mixer.

\footnotetext{
*Corresponding author: Dr. Tek Raj Gyawali

Department of Earthquake Engineering, Khwopa Engin eering College, Libali-2, Bhaktapur, Nepal Email: trgyawali@hotmail.com

(Received: 2013 Mar 02 Accepted: 2013 Oct 03)
}

JScE Vol. 2, Poush 2070
Mixing characteristic of materials when falling through vertical set-up of ESG continuous mixer, under gravity force, is illustrated in Fig 2. As show $\mathrm{n}$ in the figure, when materials are charged into ESG continuous mixer with external energy, they first impact on the inner slope surface of first unit of ESG continuous mixer (some part of materials may impact on the inner slope surface of attached

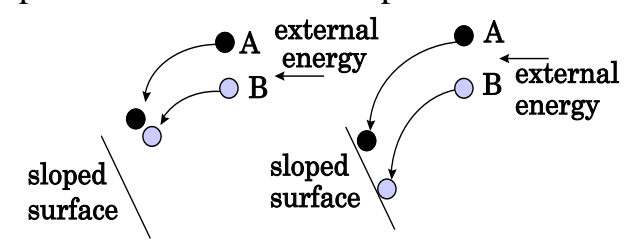
(a) collision before impact
(b) impact with slope surface
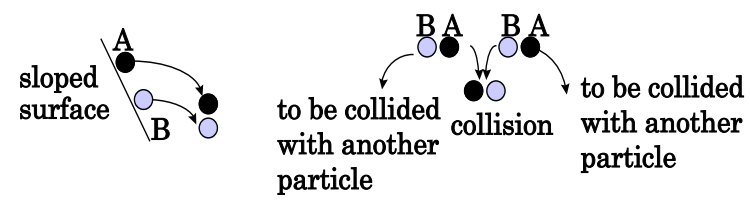
(c) collision after impact
(d) collision between more particles

Fig 1 Basic Mechanism of inter-particle collision and impact [2] 
hopper) while entering into two opening inlets. Such action makes whole materials to be split into 2 parts. Particles within materials have more chances to be collided with each other before impacting, after impacting and when falling through each openings as well.

Moreover, they have also more chances to be impacted with the inner slope surface of ESG continuous mixer unit. When they exit from the outlet of first unit, they again combine making 2 layers, in general. However, due to inter-particle collisions and impact, particles are dispersed and distributed inside each layers. Since the materials from two outlets are combined with notable momentum, this combining action creates more chances for inter-particle collisions and impact with the surface. Just after the combining action, they are again split to two parts when entering to the inlet of second unit of ESG continuous mixer. Since the outlet of first unit and inlet of second unit are crossed with each other, half of the materials discharged from one outlet layers with that of another outlet. This action crates more possibilities for different particles to be mixed with each other resulting in more uniform distribution. Continuation on splitting and recombination of materials increases the chances for inter-particle collision and impact of particles with inner slope surface when passing through number of ESG continuous mixer units.

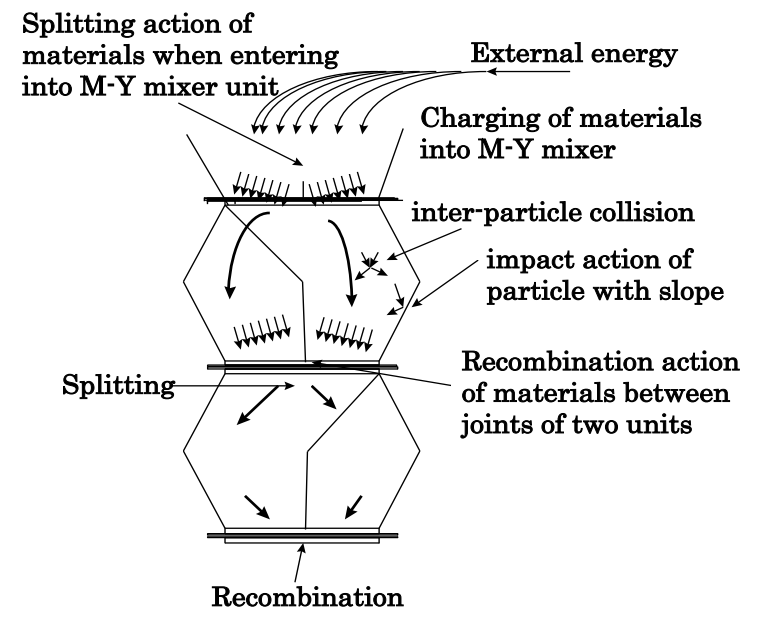

Fig 2 Expansion of basic mechanis $m$ in vertical set-up of ESG mixer [10]
With the consideration of the above mechanism, it is certainly due to mechanism of inter-particle collision and impact, which is more enhanced due to the action of the splitting and recombination of particles when passing through number of ESG continuous mixer units. However, it is obviously true that $2^{\mathrm{n}}$ theory, developed by Dr. Maeda [9], still exists forming the $2^{\mathrm{n}}$ layers of material when passing through $n$ units of ESG continuous mixer since every materials have $n$ chances of splitting and recombination. With this modified $2^{\mathrm{n}}$ theory, mixing should be possible only with the gravity effect when materials falling freely inside ESG continuous mixer units, where any external energy is not required for mixing process. In general term, it can be said that the mixing criteria inside vertical ESG continuous mixer correlates with the mixing of sand by two persons using shovels to make the uniform distribution of surface moisture thoroughly.

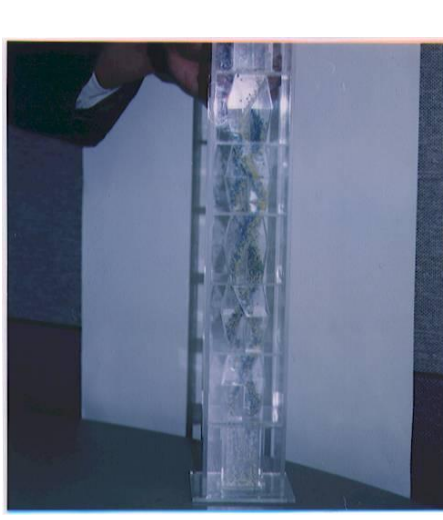

Mixing inside M-Y mixer under gravity

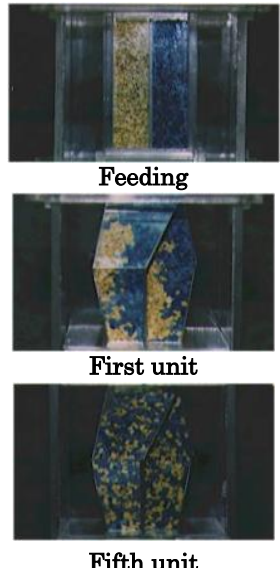

Fifth unit
Fig 3 Preliminary mixing experiment in vertical set-up of ESG continuous mixer[10]

In order to verify this assumption, mixing of two different colored grains was carried out. For this experiment, 5 units of model ESG continuous mixer, opening size of $20 \mathrm{~mm}$ by $20 \mathrm{~mm}$ and slope of $63^{\circ}$, were connected in vertical set-up. Two small vertical boxes were connected in the top of ESG continuous mixer to put the two different colored grains for feeding into two inlets. Small box was connected to the exit of bottom ESG continuous mixer unit to collect the mixed grain. The cover in between the upper boxes and first ESG continuous mixer unit was opened to feed grains into ESG continuous mixer for mixing. The falling condition of grains was carefully checked visually through 
each unit of ESG continuous mixer. With repeating this experiment, grains were collected in each unit, i.e. from first to fifth, to check the distribution condition of grains.

Fig 3 shows the condition of two different colored grains before feeding, while falling through each ESG continuous mixer unit under gravity and the mixing condition of grains in the first and fifth unit. It was observed from the experiment that materials in upper units distribute in the macro way. Then in the following units, the more distribution takes place within this macro mix and uniformity of the distribution increases in the lower units, like in $4^{\text {th }}$ and $5^{\text {th }}$ unit. It can be checked from the Fig 3 that grains in the fifth unit are evenly distributed. The collected grains from the fifth unit of ESG continuous mixer were divided into 4 portions. Those were counted to find out the distribution variation of each colored grains in each portions. The variation coefficient of distribution was only $0.4 \%$ representing very uniform distribution.

From this very preliminary mixing experiment, it was realized that mixing of larger particle size materials could be possible with the modified theory. Thus in case of vertical set-up of ESG continuous mixer, the mechanism of kneading [9] was replaced by the mechanism of inter-particle collision and impact; which is more enhanced by the action of splitting and recombination while falling through its each unit.

In order to represent such new mixing mechanism without use of any external energy, the vertical setup of ESG continuous mixer was proposed to term as Energy Saving Gravity mixer (ESG mixer)[10]. With development of this ESG mixer, the original kneading and lapping mechanism was converted again into mixing mechanism, which is still strongly alive in all type of conventional mixers.

The modified theory resulted in the reduction of the external energy to be required for mixing, since materials could be mixed when falling inside ESG continuous mixer under gravity force only. Different types of concrete materials, including RCD, dam concrete etc., were made possible to be mixed resulting in similar properties with that of conventional method. Moreover, ESG mixer has gained its category as High Performance Mixer (HPM) class over all from its comprehensive assessment by carrying out all tests compiled with the highest requirement specified by RILEM TC 150 [11].

With development of model continuous mixing system, it was verified that ESG mixer has a signific ant high efficiency for mixing different types of concrete continuously giving similar quality to that from conventional mixers [12], [13].

\section{Lite rature Review}

Fiber Reinforced Cements and concrete are firmly established as construction materials. Since the early 1960's extensive research and developments have been carried out with FRC materials leading to a wide range of practical applications [3]. Interrelation of the structural performance of FRC with material constituents, processing and mechanical properties is shown in Fig 5. It can be checked from the Fig 5 that processing is one of the most important factor to create the action of coating, dispersion, orientation and resulting in good quality. These are directly related to the structural application of FRC through its mechanical properties.

With regard to the production of FRC, many trials have been carried out, especially with the timing of adding fiber materials when mixing and other materials as well. American Concrete Institute had listed the following five methods of adding fiber materials in 1982 [1] (ACI 44-1R, 1982).

1) Feed the fibers with the aggregate and cement on the central conveyor belt.

2) Blend fibers and aggregate before charging into the mixer and then use standard mixing procedure.

3) Blend fine and coarse aggregate. Add fibers to the mixer operating at mixing speed then add water and cement.

4) Add fibers to previously charged aggregate as the water. Finally add cement and remaining water.

5) Add fibers as the last step to mixed concrete. 


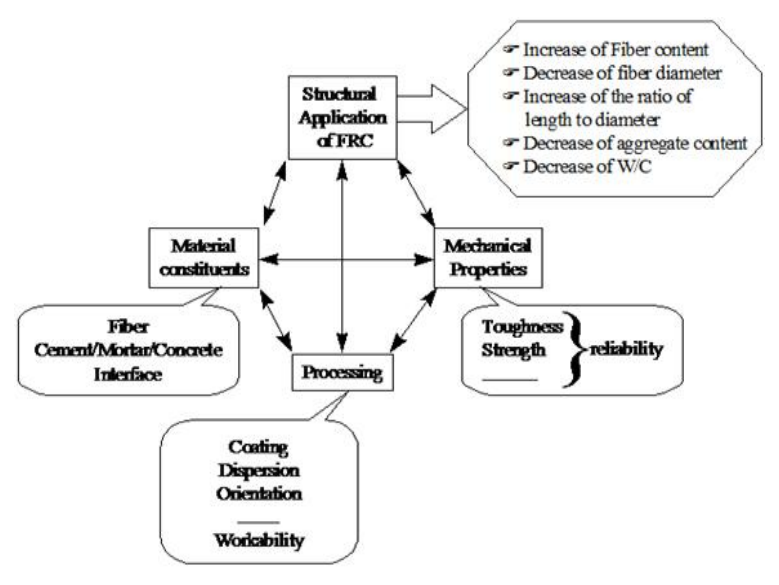

Fig 5 Chart for the evaluation of the structural application of FRC (Prof. Victor Li, University of Michigan)

However, recently American Concrete Institute, ACI 44-3R (1993), has indicated that fibers should be added to a fluid mix, either as the last stage of mixing or added to the mixer with the aggregates [2]. Both documents of ACI indicated that care should be taken to avoid fiber balling. Many recommendations were made such as to avoid the clumps of fiber adding and slow rate of adding to allow dispersion.

\section{Existing Problem and Theoretical Aspect}

In normal practice, the mixing of steel fiber reinforced concrete (SFRC) is carried out with the method: "Coarse aggregates; cement, PFA and fines are layered in the mixer. The mixer is started and the water and super plasticizer are added. After two minutes mixing fibers are added and mixing continues for 30 seconds", which is also recommended in most of the standards worldwide, i.e. ACI, JCI etc. However, it is noticed still difficult to make the even distribution of fiber materials in mixed concrete with this method in almost all types of existing mixers ever developed. Moreover, fibers may clump or form balls if more than $2 \%$ (by volume) of steel fibers are mixed in concrete. It is needless to say that the increase in the content of fiber means the increase in the requirement of external energy to make the fibers well distributed throughout the concrete. It means electric consumption of the mixer is much higher for the concrete with higher amount of fibers. In the forced type double axis mixer of $1.5 \mathrm{~m}^{3}$ capacity [8], when mixing steel fiber reinforced concrete ( SFRC) of slump about $10 \mathrm{~cm}$, load becomes double than that for ordinary concrete. This becomes 4 times in the case of slump $5 \mathrm{~cm}$. From this result, it can be understood that the load becomes extremely large when mixing the dry consistency SFRC with its slump of $2 \sim 3 \mathrm{~cm}$. In order to avoid the balling of the fibers within short time of introducing, dispensers are being used. These dispensers help the fibers to be introduced into concrete in the dispersed form, which minimize the chance for balling. However when using one dispenser with its capacity of $40 \mathrm{~kg} / \mathrm{min}$, it takes about 4 minute to introduce all fibers into the mixer for mixing SFRC with $2 \%$ fibers. It means it requires more than 5 minutes mixing SFRC with $2 \% \mathrm{SF}$ in $1.5 \mathrm{~m}^{3}$ mixer. Therefore, the main reason to limit the fiber content from $0.5 \%$ to $2 \%$ in the existing mixer should be due to the electric load and the mixing time.

In this regard, a highly expectation was made to avoid the above mentioned problems for mixing SFRC after the development of ESG mixer. It was because the problem for the electric power and the mixing time would not be existed in the case of ESG mixer. Therefore, the attempt was made to carry out the mixing work of FRC in ESG mixer. It was assumed the significance of ESG mixer for mixing FRC as mentioned in the Fig 6.

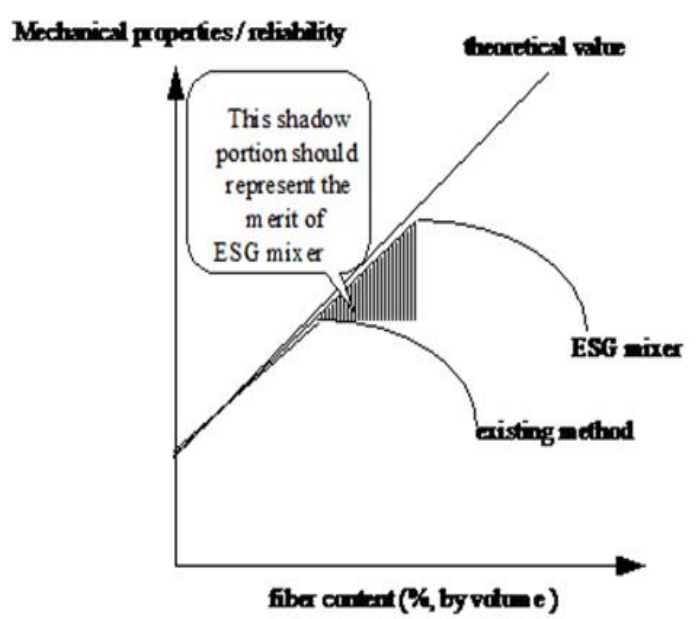

Fig 6 Criteria for the check of mixing efficiency of ESG mixer for SFRC

The properties of FRC should, in theory, be in linear with the content of SF; however, it cannot be obtained from the optimum value due to having the defect on the processing operation. If ESG mixer 
could give the result as mentioned with the shadowed portion in the Fig 6, it would significantly represent its mixing efficiency for FRC over conventional mixing method.

\section{Exiting Process}

This section briefs the application of existing mixing procedure of SFRC in ESG mixer. Two trials were carried out with two different set-up of ESG mixer. The first trial was just to see what happens and the second one was to find out the cause.

\subsection{First Trial}

In order to evaluate the mixing characteristic of ESG mixer for SFRC, the mixing experiment was carried out with simple set-up of ESG mixer that used in the preliminary mixing performance test. Six units of ESG mixer were used in this experiment. Opening size and slope of each units of ESG mixer were $270 \times 270 \mathrm{~mm}$ and $63^{\circ}$ respectively. For this test, the fiber content was only used $1.0 \%$, by volume. The mix proportion used in the experiment is shown in Table 4.

Concrete to be used in this experiment was mixed in the double axis forced type mixer. At first, 50 liter concrete was placed on the top of conveyor belt. Then the fibers were sprayed on the top of concrete and then other 50 liter concrete was placed on top of $\mathrm{SF}$, as in the sand witch method. The total length was $3 \mathrm{~m}$ and width of $40 \mathrm{~cm}$. Since the speed of conveyor-belt was $50 \mathrm{~m} / \mathrm{min}$., mixing rate of concrete was maintained as $33.3 \mathrm{l} / \mathrm{sec}$ (i.e. 120 $\mathrm{m}^{3} / \mathrm{hr}$.). Layering condition of pre-mixed concrete and fibers is shown in Photo 1. After finishing of the layering of concrete and SF, it was charged into ESG mixer by running the conveyor-belt.

The blocking of the concrete and SF was occurred during the charging time. The condition of blocking is show $\mathrm{n}$ in photo 2. Most of the mix was blocked in the joint between first and second unit of ESG mixer units. The blocked concrete was made possible to discharge by the use of high frequency vibrator. In visual check of discharged SFRC, it was noticed that coarse aggregates were discharged first and then followed by mortar. It was almost known for the difficulties of mixing SFRC with this method in ESG mixer. However, before reach the conclusion, the suspect was made that opening size of ESG mixer was not large enough for mixing SFRC than that for ordinary concrete.

\subsection{Second Trial}

For this experiment, 4 units of ESG mixer were used. The set-up of the experiment is shown in Fig 7.

Table 4 Mix proportion of SFRC used in first trial

\begin{tabular}{|c|c|c|c|c|c|c|c|c|c|}
\hline \multirow{2}{*}{$\begin{array}{l}\mathrm{G}_{\max } \\
(\mathrm{mm})\end{array}$} & \multirow{2}{*}{$\begin{array}{c}\text { Slump } \\
(\mathrm{cm})\end{array}$} & \multirow{2}{*}{$\begin{array}{l}\text { W/C } \\
(\%)\end{array}$} & \multirow{2}{*}{$\begin{array}{l}\text { s/a } \\
(\%)\end{array}$} & \multicolumn{6}{|c|}{ Unit content $\left(\mathrm{kg} / \mathrm{m}^{3}\right)$} \\
\hline & & & & Cement & Water & Sand & Gravel & Admixture & SF \\
\hline 20 & 5 & 41.3 & 57.8 & 415 & 170 & 997 & 750 & 4.15 & 80 \\
\hline
\end{tabular}

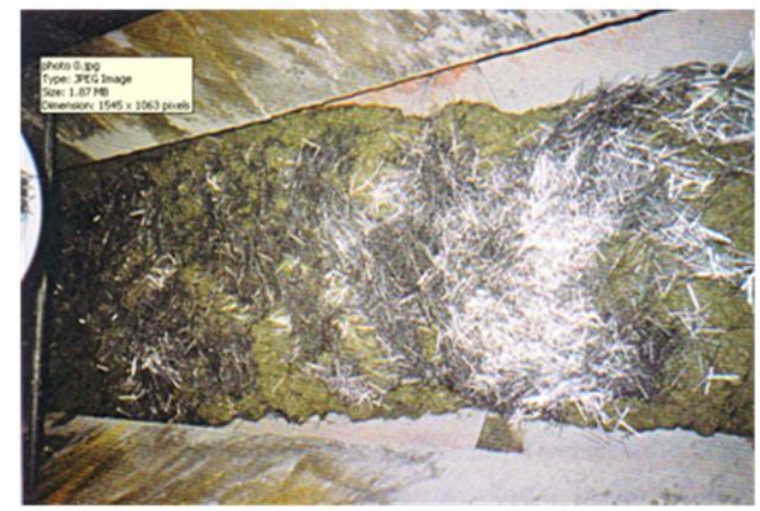

Photo 1 Condition of layered pre-mixed concrete and SF on conveyor-belt before charging

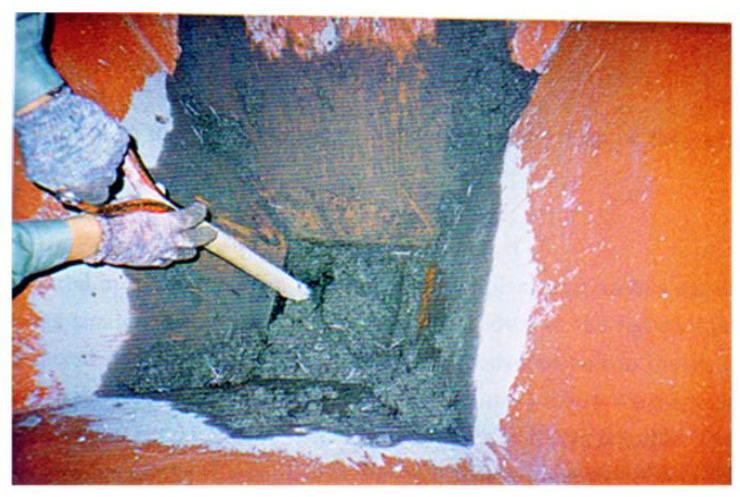

Photo 2 Condition of pre-mixed concrete and SF blocked 


\subsubsection{Experiment Procedure}

Concrete required in this experiment was mixed in the plant near to this set-up. Its mix proportion was similar to that used in first trial. As shown in the Fig 7, the 100 liter batched pre-mixed concrete was first placed on the conveyor-belt in the length of $5 \mathrm{~m}$ resulting in its thickness of $6 \mathrm{~cm}$. Then $16 \mathrm{~kg}$ ( $2 \%$ by volume) fibers were sprayed on the top of concrete maintaining uniform distribution as much as it was possible. The mix was then charged into hopper by running conveyor-belt. It was done twice in order to carry out the mixing of 200 liter SFRC in ESG mixer. The hopper containing the macro-mix of premixed concrete and SF was lifted by crane to the top of ESG mixer and then charged for mixing. The judgment was made from SFRC collected in hopper below ESG mixer.

\subsubsection{Experiment results}

The slump of concrete was noted $18.5 \mathrm{~cm}$ with its temperature of $18^{\circ}$ at its elapsed time of 30 minutes after mixing. The condition of the macro-mix of the pre-mixed concrete and SF is shown in Fig 8. It was noticed that the SF and concrete were separately dropped from the conveyor-belt to hopper. Intermixing even in the macro-level was not existed. Two vertical layers of concrete and SF were formed inside the hopper which can be clearly noticed with the condition of its upper surface shown in photo 3 .
The mixed condition of SFRC is illustrated in 9 . During the mixing action, it was noticed that only concrete was discharged from the exits of ESG mixer followed by mix of SF and concrete and finally only SF. In mixed SFRC, distribution condition of SF was very uneven.

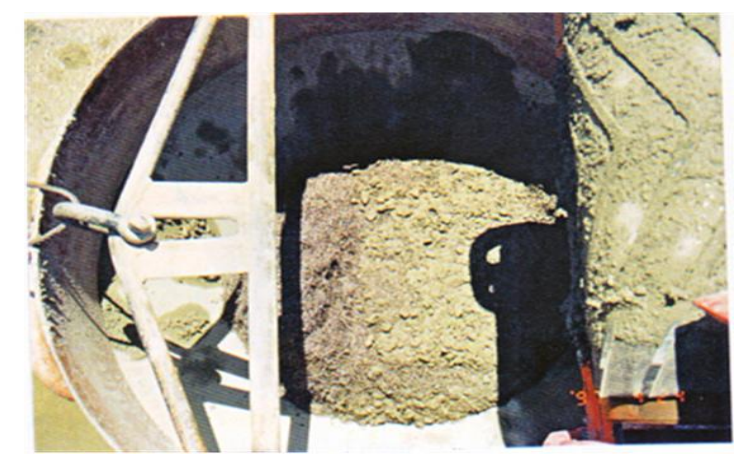

Photo 3 Condition of the macro-mix of pre-mixed

From these both trials, it was understood that fibers cannot be dispersed inside the concrete when falling through each units of ESG mixer under gravity force. It is due to the different falling characteristics of two phases. Since concrete is viscous and wet, it falls as sliding through the surface of ESG mixer. In other hand, due to the large aspect ratio of SF, they neither be bounced on the inner surface of ESG mixer nor be dispersed inside concrete due to having less inter-particle collision action.

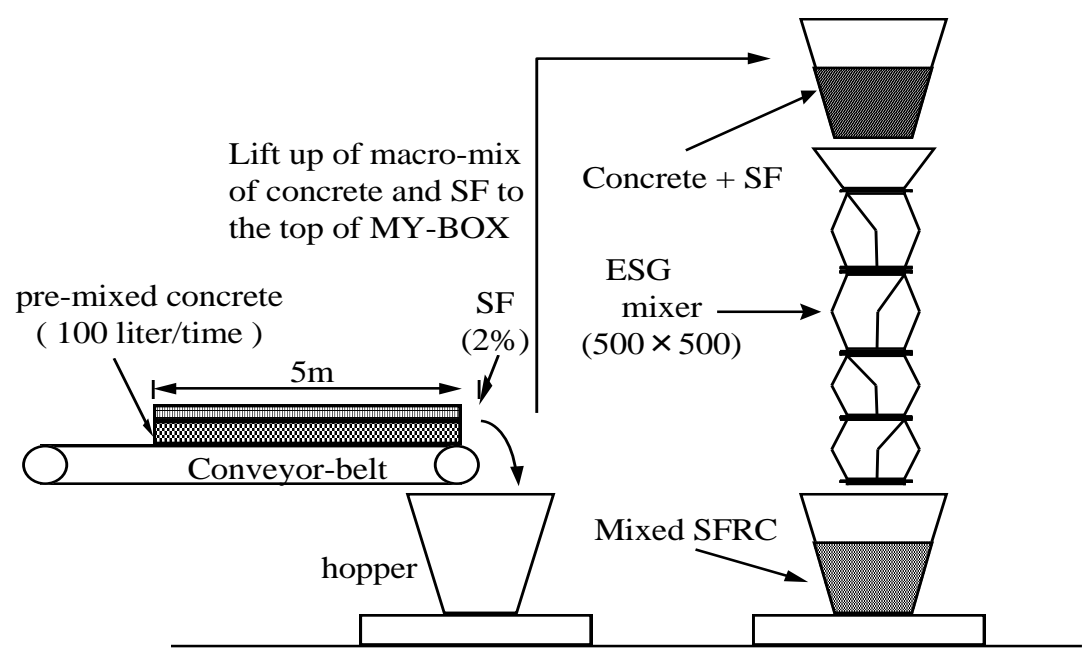

Fig 7 Mixing method of SFRC using ESG mixer in second trial 
That is why it was concluded that the existing mixing procedure of SFRC $w$ as not suitable to apply in ESG mixer. One may claim from Fig 5 that better quality of SFRC could be achieved if the mixing was carried out for long time in second trial. But this attempt was avoided with the evidence of lot of fibers remained inside ESG mixer units, show $\mathrm{n}$ in photo 4 , which would be cause of blocking in further mixing as it $w$ as happened in first trial.

\section{New Process: Development Of "Pre-Mix Method"}

As described in section 4, the existing mixing procedure of SFRC was no more use for ESG mixer. The practical study was made by many trials to find out any relevant way to adopt for mixing SFRC in ESG mixer. Through many trials, a new method, namely "Pre-mix Method" was developed. This section describes about this method.

\subsection{Experiment Procedure}

Aggregates and fibers were first mixed in ESG mixer and the mix was called as "Pre-mix". Then, pre-mix and pre-mixed mortar was charged into ESG mixer for mixing SFRC. This method of mixing SFRC in ESG mixer was named as "Pre-mix Method". Generally, whole mixing procedure, in ESG mixer, was divided into 3 parts as: dry mixing of aggregates and fibers (pre-mix), mixing of mortar, and then, mixing of SFRC. The latter two were similar process to that used for mixing ordinary concrete.

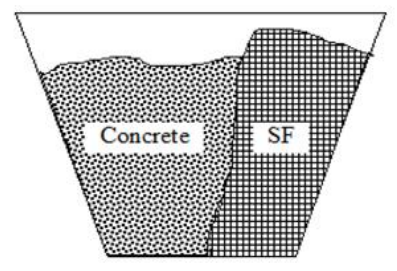

Fig 8 Condition of macro-mix of pre-mixed concrete and SF before charging into ESG mixer concrete and SF before charging into ESG mixer

Aggregates to be used in pre-mix might be coarse aggregates only or also fine aggregates if required, which depend upon the fiber contents to be added. For lower content of fibers (i.e. $=$ or $<2 \%$ by volume), only coarse aggregates were used and layering was done in two layers as aggregates being on bottom and fibers on top. For higher content of fibers (i.e. $>2 \%$ by volume ), fine aggregate was also used and layering was done in sand witch with coarse aggregates in the bottom and then followed by half content of SF, fine aggregates and finally half percent of SF on the top. The amount of fine aggregate to be used in pre-mix also depends upon the content of SF added. Increase in content of SF means the increased amount of fine aggregates in pre-mix. The basic principle for the selection of amount of fine aggregate should be such that each and every fiber should be dispersed inside aggregates one by one in the most uniform state avoiding any clumps.

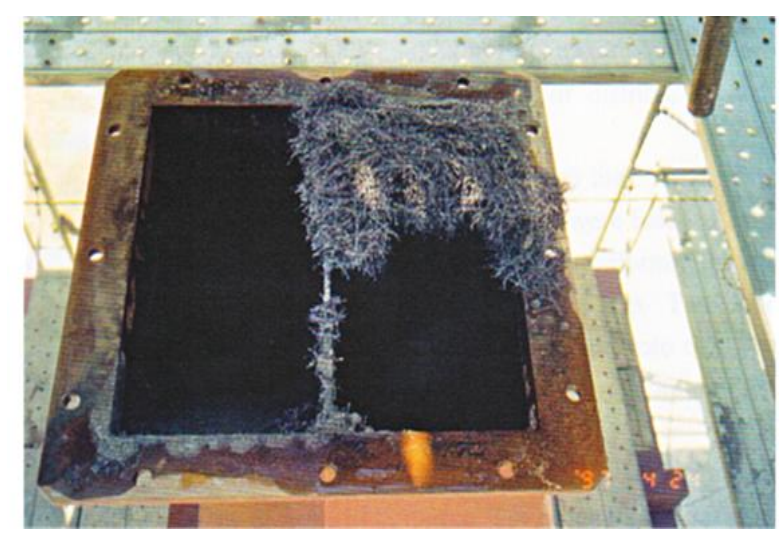

Photo 4 Condition of fiber remaining inside

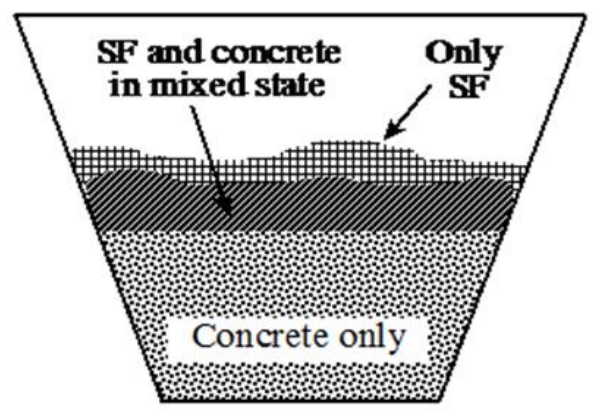

Fig 9 Condition of SFRC mixed in ESG mixer ESG mixer in second trial

In order to evaluate the possibility of this new method in ESG mixer, very preliminary tests were carried out in the initial stage. The first target was to examine whether all ingredients can pass through every units of ESG mixer without any blockage, which was the major problem with the existing 
mixing method in ESG mixer. And, the second was to judge its efficiency for mixing SFRC in the sense of distribution and coating conditions of fibers and non existence of any fiber balls.

The mixing volume of SFRC per one time was fixed as 100 liter. At the first step of mixing work, all raw materials required for one mixing time were batched by weighing. The batched aggregates were first layered on conveyor-belt uniformly throughout the designed length and fibers were sprayed uniformly on its top. The condition of aggregates and fibers layered on the conveyor-belt is shown in photo 5 . Then it was charged into ESG mixer for mixing work. Photo 6 shows the condition of the dry mix of $\mathrm{SF}$ and aggregate after pre-mixing in ESG mixer.

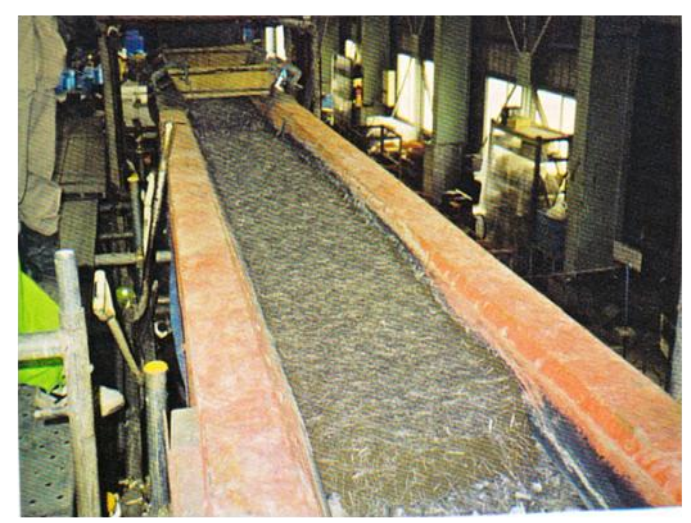

Photo 5 Condition of layered aggregates and fibers on top of conveyor-belt
Mortar was mixed in the existing forced action double ax is mixer. Before mix ing the real mix, one mix was mixed for buttering purpose. The required amount of pre-mixed mortar was batched by weighing. The batched mortar and pre-mix were layered on conveyor-belt maintaining pre-mix on the bottom and the mortar on top. Then the mix was charged into ESG mixer for mixing SFRC. Fig 10 gives the overall image of mixing procedure of SFRC using "Pre-mix Method". In the Fig 10, confusion should not be made that whether this mixing procedure should require two set-up of ESG mixer. For better understanding, same set-up of ESG mixer is shown in left and right hand side for premixing and mixing of SFRC respectively, where the former is followed by the latter one.

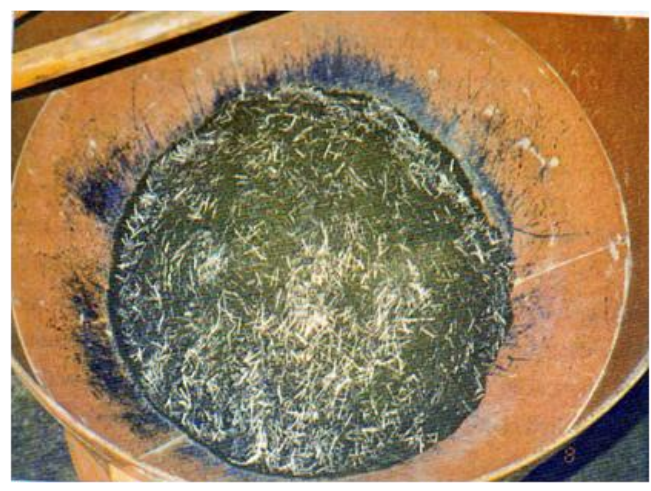

Photo 6 Condition of pre-mix (dry mix of aggregates and fibers, $\mathrm{SF}=4 \%$, by volu me )

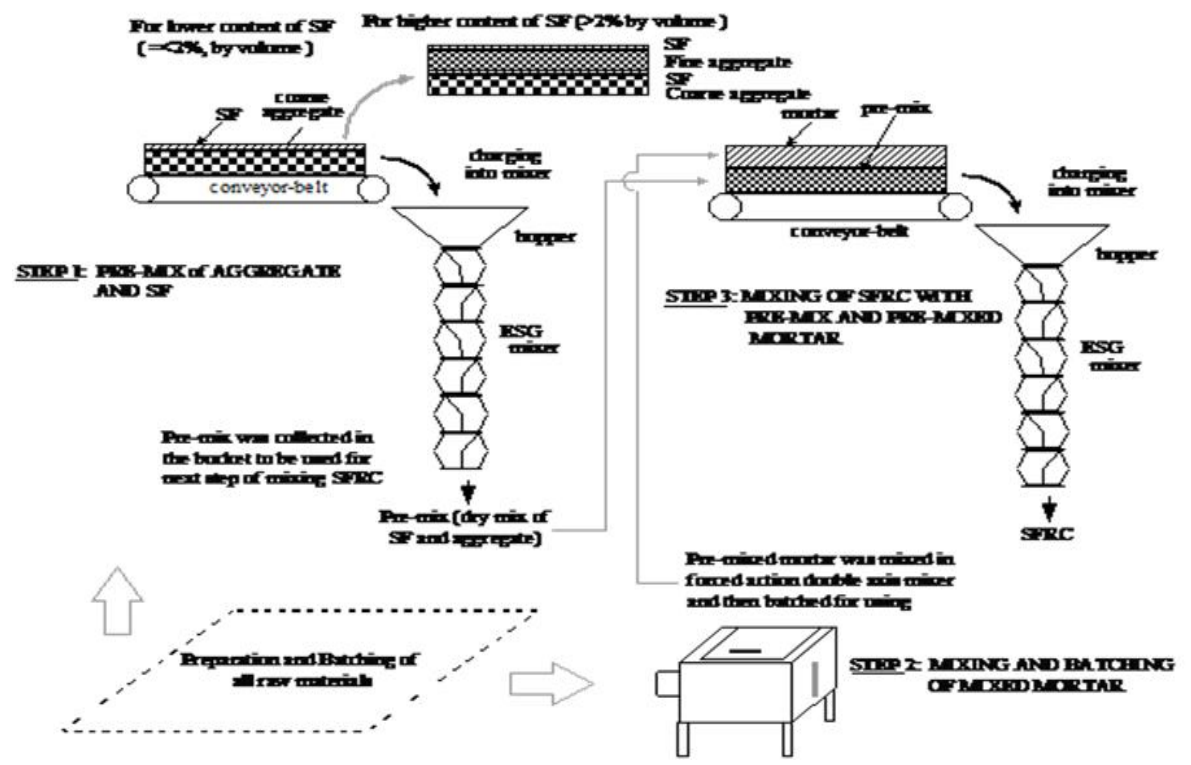

Fig 10 Procedure for mixing of SFRC in ESG mixing system 
Table 5 Properties of steel fibers used in mixing experiment

\begin{tabular}{ccccccccc}
\hline Length & Mass & $\begin{array}{c}\text { Cross-section } \\
\text { area }\end{array}$ & $\begin{array}{c}\text { Cross-section } \\
\text { diameter }\end{array}$ & \multicolumn{2}{c}{$\begin{array}{c}\text { Tensile } \\
\text { strength }\end{array}$} & \multicolumn{4}{c}{$\begin{array}{c}\text { Chemical content } \\
\text { (Wt. \%) }\end{array}$} \\
\cline { 6 - 9 } & $(\mathrm{mm})$ & $\left(\mathrm{mm}^{2}\right)$ & $(\mathrm{mm})$ & $\left(\mathrm{N} / \mathrm{mm}^{2}\right)$ & $\mathrm{C}$ & $\mathrm{MN}$ & $\mathrm{P}$ & $\mathrm{S}$ \\
30.0 & 69 & 0.293 & 0.611 & 119 & 0.07 & 0.24 & 0.018 & 0.006 \\
\hline
\end{tabular}

Table 6 Test results of SFRC in trials

\begin{tabular}{ccccccccccc}
\hline Mixer & Date & $\begin{array}{c}\mathrm{SF} \\
\text { type }\end{array}$ & & $\begin{array}{c}\mathrm{W} / \mathrm{C} \\
(\%)\end{array}$ & $\begin{array}{c}\mathrm{s} / \mathrm{a} \\
(\%)\end{array}$ & $\begin{array}{c}\mathrm{W} \\
\left(\mathrm{kg} / \mathrm{m}^{3}\right)\end{array}$ & $\begin{array}{c}\text { Concrete } \\
\text { temp. }\left({ }^{\circ} \mathrm{C}\right)\end{array}$ & $\begin{array}{c}\text { Slump } \\
(\mathrm{cm})\end{array}$ & $\begin{array}{c}\text { Air } \\
(\%)\end{array}$ & \multicolumn{2}{c}{7 days Strength (Mpa) } \\
\hline Forced & 6.8 .97 & 3.0 & 41.4 & 67 & 207 & 26.0 & 8.0 & 4.8 & 40.3 & 9.7 \\
\hline & 6.8 .97 & 3.0 & 41.4 & 67 & 207 & 26.5 & 4.0 & 3.0 & 41.8 & 10.4 \\
ESG & 6.8 .97 & 4.0 & 41.4 & 67 & 207 & 24.0 & 1.0 & 2.9 & 43.2 & 11.0 \\
mixer & 6.16 .97 & 2.0 & 50 & 65 & 200 & 26.5 & 12.0 & 3.9 & - & 6.8 \\
& 6.16 .97 & 4.0 & 50 & 75 & 235 & 25.0 & 10.0 & 4.0 & - & 12.5 \\
\hline Forced & 6.19 .97 & 2.0 & 45 & 50 & 200 & 22.0 & 6.8 & - & - & 7.5 \\
\hline ESG & 6.26 .97 & 2.0 & 45 & 50 & 200 & - & - & - & 34.0 & 7.1 \\
mixer & 6.26 .97 & 4.0 & 45 & 65 & 235 & - & - & - & 37.8 & 10.7 \\
\hline
\end{tabular}

\section{Result and Discussion}

Properties of steel fibers used in this experiment, which were available from maker, are shown in Table 5 .

The pre-mix was carried out with SF and whole amount of coarse aggregates for SFRC with SF content of $2 \%$. For SF content of $4 \%, 50 \%$ of fine aggregate was used for pre-mix and another $50 \%$ was used in pre-mixed mortar. It was understood from the visual check that the distribution condition of SF was quite uniform in both cases.

Mixing condition of SFRC with its $4 \%$ are shown in photos 7. In visual check it was agreed that the SF were uniformly distributed throughout the concrete and well coated in both cases. Their test results obtained in different trials are shown in Table 6.

There are few points to be noted in the table. When analyzing data on first three rows, it seems that the strength of SFRC mixed in ESG mixer seems to be similar or slightly higher than that of conventional; whereas values of slump and air content are slightly decreased. It should be due to the elapsed time of pre-mixed mortar consumed. Moreover, it is also known that for the same base concrete, the increase of fiber content may not have significant effect in increase of strength properties. This result has backed up the recommendation of JIS for the design of appropriate mix proportion for given different fiber contents in order to achieve the significant effectiveness of fiber materials in strength, especially flexural strength and toughness.

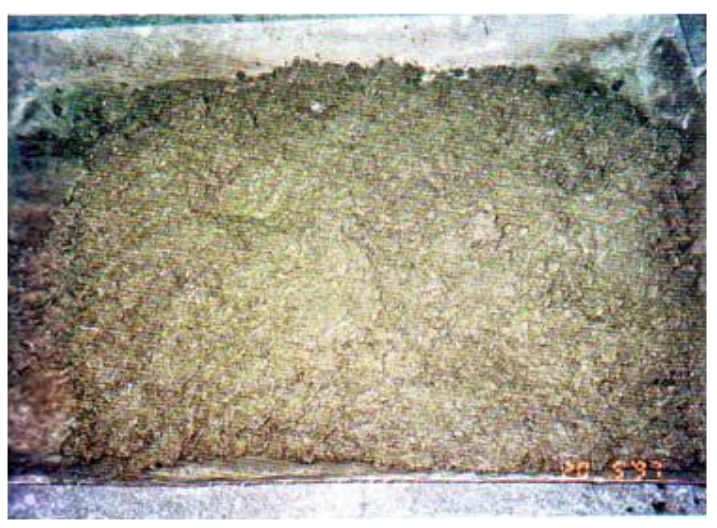

Photo 7 Mixing condition of SFRC ( $\mathrm{SF}=4 \%$, by volume $)$

SFRC mixed in ESG mixer on 6.16.97 show s that its flexural strength is increased $84 \%$ (i.e. from 6.8 $\mathrm{MPa}$ to $12.5 \mathrm{MPa}$ ) when fiber content is increased from $2 \%$ to $4 \%$, by volume. How ever, this result is found as the increment of only $34 \%$ in SFRC mixed on 6.26.97 (Table 5). Unit water content of the corresponding mixes on different days is same. But the differences are on water cement ratios and s/a. It has given a good lesson from these trial tests that the appropriate selection of the mix proportion gives the improved strength properties when it is mixed in 
ESG mixer. The optimum limit of fiber content can overcome the upper limit of JIS which was recommended with the consideration of the mixing time and electric load. As one of the most noted merit point, both of these factors are very negligibly affected in case of mixing in ESG mixer.

From these different trial tests, it was come to the point that ESG mixer can give the required quality of SFRC (similar to that of conventional mixer) when mixing with the newly developed "Pre-mix Method". Moreover, it was possible to increase the fiber content more than the optimum value recommended in the existing mixers resulting in significant effect of increased fibers on the mechanical properties of SFRC.

\section{Conclusion}

The existing conventional method of mixing SFRC was no more possible in ESG mixer due to the blocking of fibers inside it. In order to overcome this problem, new method of mixing procedure, called "Pre-mix Method" was developed, in which fibers were first mixed with dry aggregates ( coarse aggregate and also fine when necessary ) in ESG mixer to obtain the dry mix of fibers and aggregates. Then, mixing of SFRC was carried out by mixing pre-mix with mortar in ESG mixer. With this developed method, content of fiber was able to be increased with achievement of good result as required.

\section{References}

[1] ACI Committee 44, "State-of-the-Art Report on Fiber Reinforced Concrete", ACI 44. IR, ACI, Detroit,pp.9, 1982.

[2] ACI Committee 44, "Guide for Specifying, Proportioning, Mixing, Placing, and Finishing Steel Fiber Reinforced Concrete", ACI 44. 3R-93, ACI, Detroit, 1993.

[3] Barr, B.I.G., "Fiber Reinforced Concrete-Where do we go from here?", Fiber Reinforced Cement and Concrete, Proceedings of the fourth RILEM International Symposium, Edited by R. N. Swamy, E\&FN SPON, London, UK, pp. 3 11, July 20 23, 1992.

[4] Bartos P.J.M., Hoy C.W., "Interaction of Particles in Fiber Reinforced Concrete", Proceedings of the
International RILEM Conference on Production Methods and Workability of Concrete, edited by P.J.M. Bartos, D.L. Marrs \& D.J. Cleland, E\&FN Spon, London, UK, pp. 461 462, 199

[5] Hoy C.W., "Mixing and Mix Proportioning of Fiber Reinforced Concrete", PhD Thesis, University of Paisley, March 1998.

[6] Hoy C.W., and Bartos, P.J.M., "Mixing of Fiber Reinforced Concrete", Presented at the 1997 Spring Convention, American Concrete Institute, Seattle, Washington, U.S.A., April 6 11, 1997.

[7] Japan Concrete Institute, "JCI Standards for Test Methods of Fiber Reinforced Concrete", JCI-SF (in Japanese).

[8] Japan Society of Civil Engineers, "Recommendation on Design and Construction of Fiber Reinforced Concrete", Concrete Library, No. 50, March, 1984 (In Japanese).

[9] Maeda K., "Development of a New Mixer Based on the Kneading Method", Doctoral Dissertation Submitted to the University of Tokyo, Japan, 1995.

[10] Gyawali, T.R., Development of Less Energy Required and Gravity Effect Continuous Mixer Based on New Mixing Theory, PhD Thesis, University of Tokyo, 1999.

[11] Bartos P.J.M., “Assessment of Performance of M-Y Mixer”, Final Report, University of Paisley, UK, 1999.

[12] Uchida A., Yamada K., Matabee, K.M.and Gyawali, T.R., "Development of New Concrete Mixing System Using the New Type of Continuous Mixer "MY-BOX", '97 International Three Gorges Project Technical Seminar, Yicjang China, pp. 1-10, 1997.

[13] Matabee, K.M., Yamada K., Uchida, A., and Gyawali, T.R., " The Use of New Continuous Mixer "MY-BOX" for Mixing RCD and Dam Concrete", International Symposium on Roller Compacted Concrete Dam, Chengdu, China, pp. 679-691, 1999. 